\title{
Social capital and the small micro enterprise financing research in China_-Golden Triangle area in Shandong and Fujian as an Example \\ Lu-Han XU ${ }^{1, a,{ }^{*}}$ \\ ${ }^{1}$ School of Business, Shandong University (Weihai), Weihai, 264200, China \\ axuluhan0881@163.com \\ ${ }^{*}$ Corresponding author
}

Keywords: social capital,small and micro enterprises,financing.

\begin{abstract}
In this paper,Shandong and Fujian Golden Triangle region,an analysis of the impact of bank-enterprise relations,social relations, government relations and other social capital to small and micro enterprises in financing activities. The study found that small and micro enterprises are rare in corporate management experience working in the banking,contact with local chambers of commerce,government and research institutions are less important aspects of its financing difficulties caused.Also a good relationship between banks,fixed source and suppliers in favor of the study to obtain loans from the bank,but this level is relatively low promote.
\end{abstract}

\section{Introduction}

Introduction of small and micro enterprises at present though smaller,but numerous, with less investment,short,quick, adaptable and other obvious advantage of being able to fully utilize all the limited available resources,to adjust the structure,expanding employment and promoting technological progress and institutional innovation plays an extremely important role.However,small and micro enterprises in the development process there are many problems,especially in the current economy continues downward,the continuous appreciation of the RMB in the background,small and micro enterprises increasingly exhibit the characteristics of weak competitiveness, financing difficulties of small and micro enterprises become restricted development bottleneck.

A.The concept of social capital research

Social capital,the concept was pioneered by Hanifan(1961)was presented at the beginning of the last century.Domestic and foreign scholars on the definition of social capital can be broadly classified into the following categories:

One is the network theory.Bourdieu(1985)defines the social capital as "the aggregate of the actual or potential resources, these resources and composed of a relationship of mutual default or recognition of the persistence network are inseparable, and these relations are more or less institutionalized".

Two is the resource theory.Lin Nan(2001)put forward the theory of social resources,social capital is defined as"an embedded in social structures and can be obtained or flow through direct or indirect social relation resources".

Three is the ability.Bian Yanjie(2000)argues that enterprise social capital is "ability of the enterprise to obtain scarce resources with the various aspects in the economic field set up by the network."

B.study on the relationship between social capital and enterprise financing

Foreign scholar Coleman firstly inspects the social capital on the financial impact on the economy and finance,think social capital to improve the level of trust between people.In China,Yan 
Jun(2008)constructs a theoretical model between the trust and financing structure, and has carried on the empirical analysis,results of the owners of private networks and trust pattern of difference sequence is the influence factor of financing availability.

In order to solve the small and micro businesses generally have high financing costs and credit rationing and other financing constraints in the process of financing,related research have put forward:establish the financial support of the relevant laws and regulations, improve the financial policy and system,give small and micro businesses more concessions for advice on financial subsidies and tax.However, the social capital as a hidden in the social network resources,prominent role in China's economic transition, which can broaden the financing channels and reduce the information asymmetry in the process of financing,financing constraints.

\section{Field Research on The Impact Of Social Capital Financing Of Small And Micro Enterprise}

At present,the research on the financing of social capital on the enterprise is less, the majority of scholars from the"social relations, social network"to explain its impact on corporate financing constraints. Such as Chakravarty(1999) pay attention to the influence of social network on enterprise's financing behavior,put forward the relationship finance theory.Through the above analysis,social capital as a hidden social resources, is built on the basis of repeated trading networks, its internal social relations, social network can significantly reduce the degree of asymmetric information in the enterprise financing process. More and more social capital owned by the enterprise,it can make use of social resources more abundant,can increase the enterprise financing opportunities,to broaden the financing channels,reduce financing constraints. Therefore,this paper puts forward hypothesis:the more social capital,Small and micro businesses financing ability.Research results are as follows:

Table 1 is the main channel of enterprise financing,from the chart we can see:the Small and micro businesses also use its own funds and bank loans, credit unions to get money,accounted for $49.2 \%$ and 24.2\%; at the same time,borrowing from the relatives and friends or rely on government support and other effective way,which accounted for $17.2 \%$ and 3.9\%.The small and micro businesses due to the need of their number,raising time is tight,so most business owners to choose its own funds or loans to relatives and friends.But in the Small and micro businesses to grow the initial stage,the government capital and banks,credit cooperatives loans also plays a great support.

Table 1

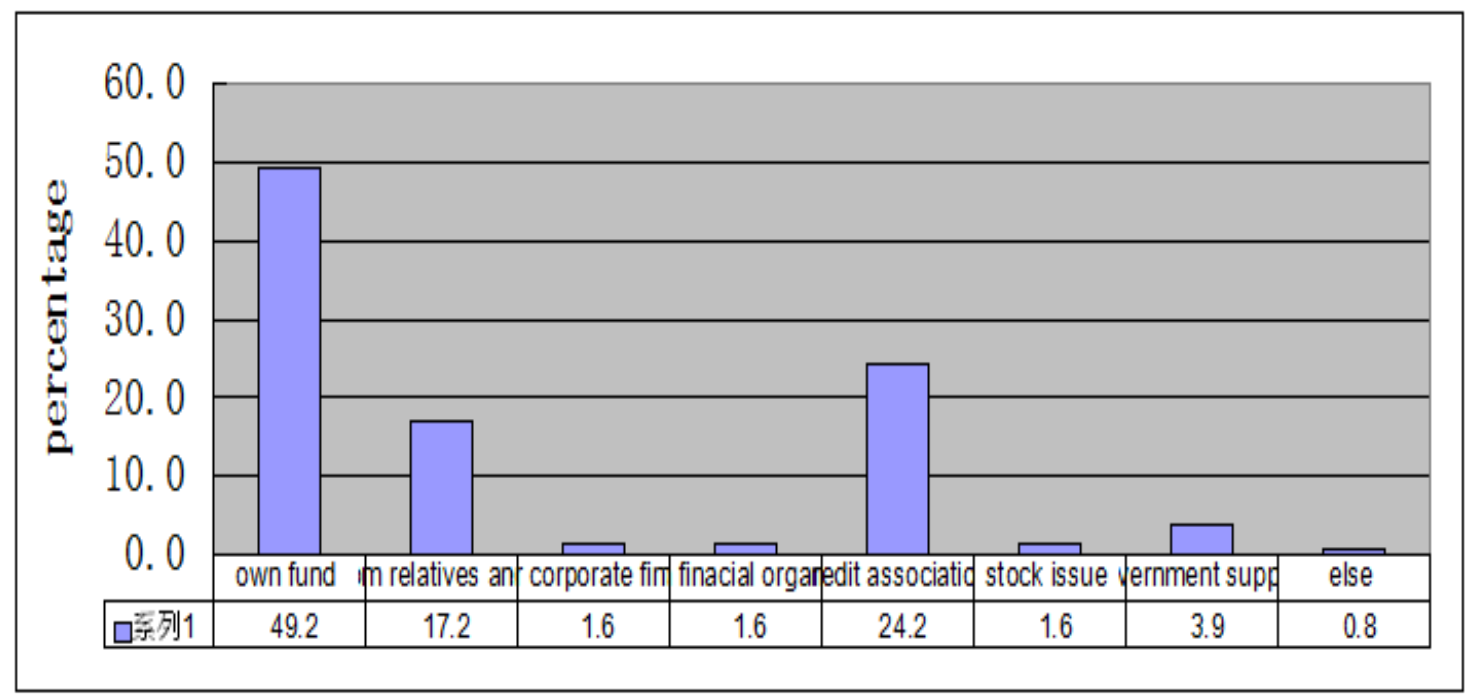

Table 2 shows,Small and micro businesses to establish information communication mechanisms 
and relationship between banks in general than did not build good relationship between banks and enterprises loan ability.Can be seen in Table3,small and micro businesses76.9\% main hopes to maintain good relationship with banks to reduce or eliminate the dependence of the Guarantee corporation.This also reflects the good relations with banks to Small and micro businesses financing.

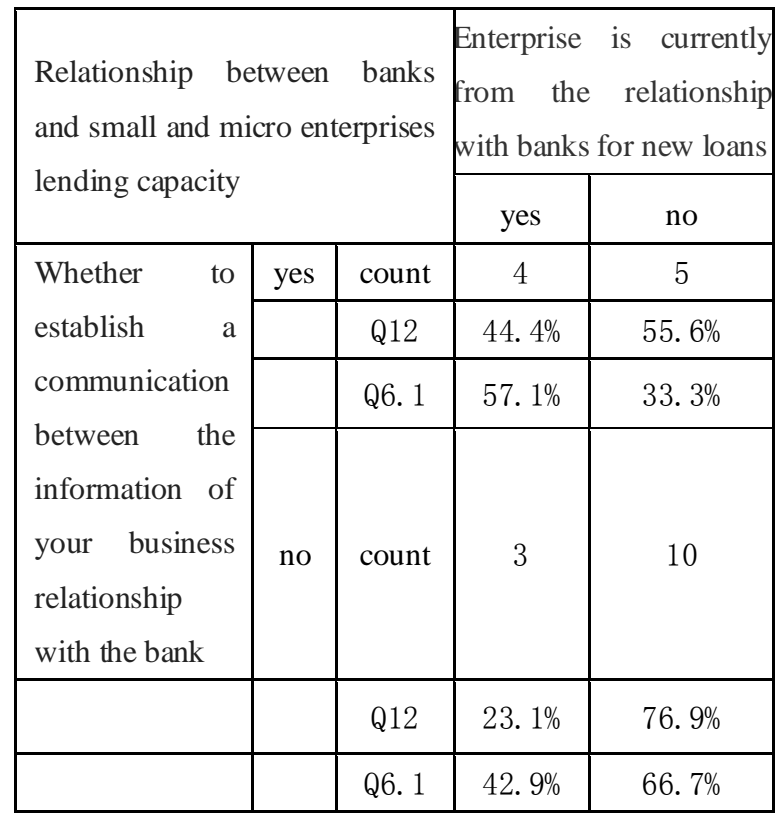

Table 2 the relationship between banks and small business lending capacity analysis of cross-tables.

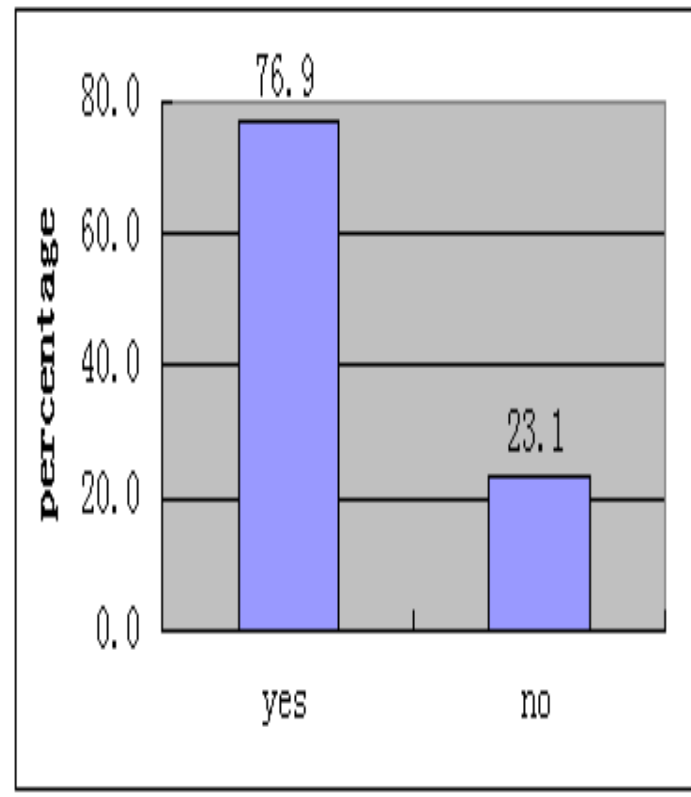

Table 3 you want to through a good relationship relationship with the bank to reduce or eliminate reliance on the company's guarantee

Table 4, 5 showed the close relationship between the $1.6 \%$ of Small and micro businesses and local associations or chambers of Commerce, $6.6 \%$ of the enterprises and associations more contacts, $6.3 \%$ of the enterprises to contact with local universities or research institutions more.

Table 6, 7 showed that $87.1 \%$ of the surveyed enterprises have fixed suppliers and fixed customers, and business is generally more than three

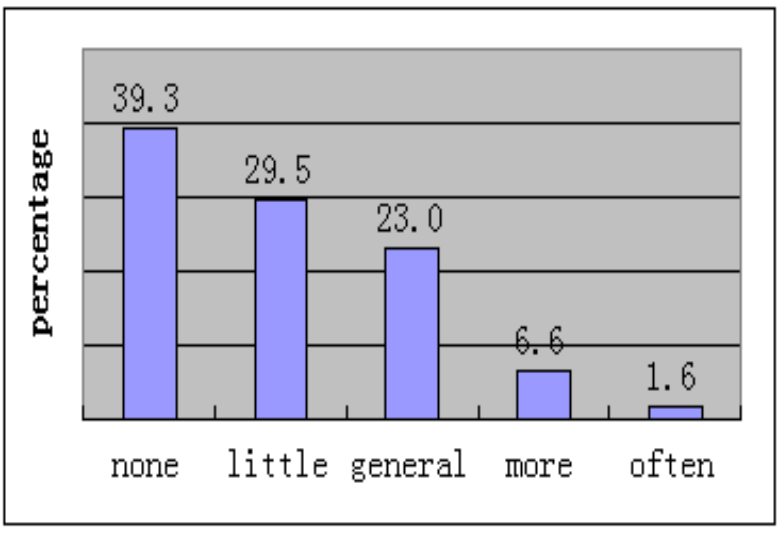

Table 4 business with the local association or chamber of commerce contact

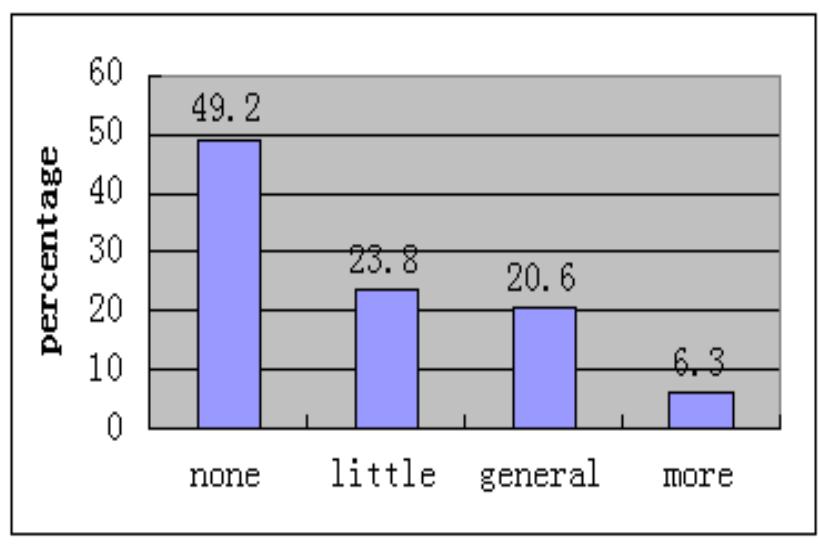

Table 5 expensive enterprise and local university, scientific research institution relation 


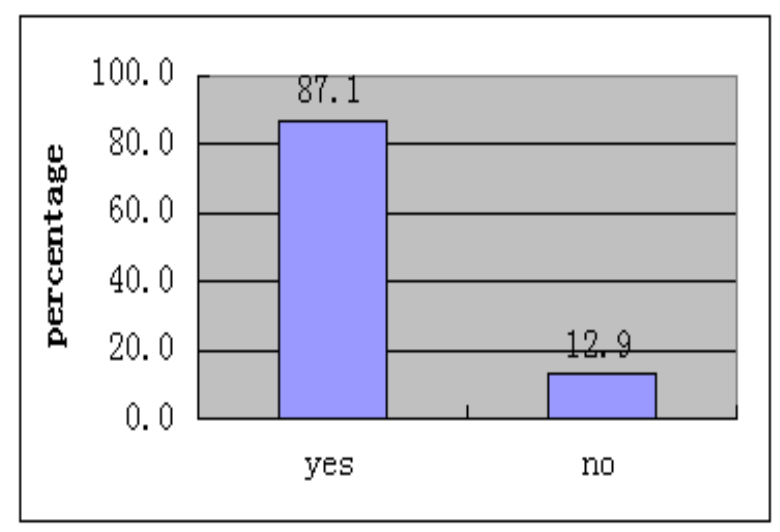

Table 6 does your company have a fixed supplier(business with more than three times)

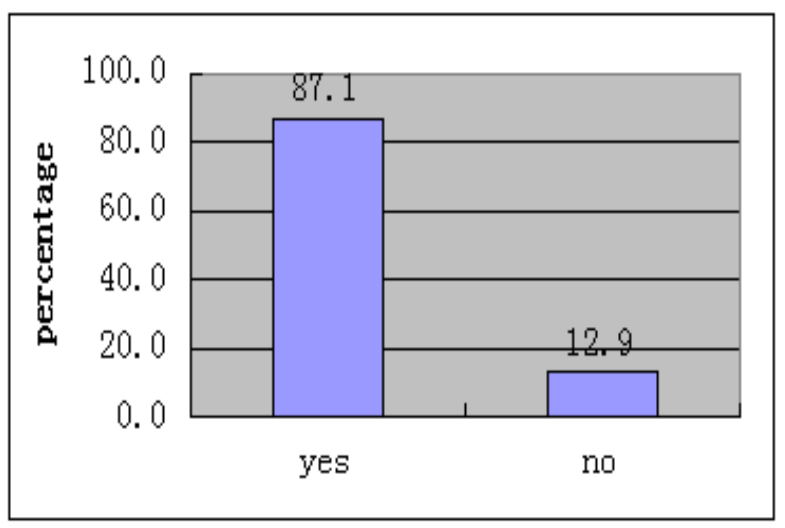

Table 7 does your company have a fixed customer (business with more than three times)

\section{Four Conclusions And Suggestions}

Through the above research,this paper verifies the hypothesis,namely the higher social capital,Small and micro businesses financing ability. Mainly in the:

1) good relationship between banks and enterprises to help enterprises to obtain loans from the bank that relationship lending can promote Small and micro businesses loans;2) corporate executives have banking experience will greatly increase the Small and micro businesses activities lending opportunities;3) Small and micro businesses have relatively fixed source and supplier of its operation is stable, in the stability and development to achieve a win-win opportunity is bigger, it is also easier to get loan opportunity.

To Rich Small and micro businesses social capital, thereby alleviating financing constraints, this paper makes the following recommendations:

1) Small and micro businesses should improve their credit level and core competitiveness, improving the relationship between banks and enterprises. Small and micro businesses to establish the correct concept, actively seeking innovation, development, actively cooperate with the government and bank's efforts, and continuously improve the relationship between banks and enterprises, through its own credit level, the enterprise competition ability, get more financing.

2) local chambers of Commerce and associations should actively with Small and micro businesses, help Small and micro businesses and understanding of the local industry information and employment information, to establish a Small and micro businesses with the local workers and Small and micro businesses with local banks and other financial institutions in close contact, so as to effectively improve the Small and micro businesses. The difficult employment, raise funds difficult problem.

3) the establishment of security mechanisms of relationship financing. The guarantee agency information superiority to the local Small and micro businesses, provide a variety of financing guarantee, as Small and micro businesses promising support and the urgent need for short-term funds at the same time, the Guarantee Corporation to share risk. The agreement between the Guarantee Corporation and banks and cooperative relations, the rapid establishment of banks and small micro financing business platform.

\section{References}

[1]Nan Lin. Social Capital: A Theory of Social Structure and Action [J]. Cambridge University Press, 2001:19-29. 
[2] Bai C, Lu J, Z Tao .Property Rights Protection and Access to Bank Loans. Economics of transition, 2006, (14):611-628.

[3] Zhou W B. Bank Financing in China's Private Sector: the Payoffs of Political Capital. World Development, 2009,(27):787-799.

[4] Bian Yanjie, Qiu Haixiong. Social capital and its function of [J]. China social science, 2000 (2): $87-100$

[5] Yan Jun. The owners of private SMEs financing behavior of [D]. Wuhan: Huazhong Agricultural University doctorate thesis.2008 year in May

[6] Chen Yongjiang, Chai Youlan. Social capital financing of the investigation and analysis of [J]. accounting research relies on private enterprises, 2007 (12): 61-64 